\title{
Bifocal Hybrid Laser Beam Welding and Friction Stir Welding of Aluminium Extrusion Components
}

\author{
Michael F. Zaeh ${ }^{1, a}$, Paul Gebhard ${ }^{1, b}$, Sonja Huber ${ }^{1, c}$, Markus Ruhstorfer ${ }^{1, d}$ \\ ${ }^{1}$ Institute for Machine Tools and Industrial Management iwb, Technische Universität München, \\ Boltzmannstr. 15, 85748 Garching, Germany \\ amichael.zaeh@iwb.tum.de, bpaul.gebhard@iwb.tum.de, 'sonja.huber@iwb.tum.de, \\ dmarkus.ruhstorfer@iwb.tum.de
}

Keywords: laser welding, hybrid, bifocal, aluminium, friction stir welding, reinforced extrusion, EN AW-6060

\begin{abstract}
On a global market, new products are subject to rising requirements regarding strength and quality. Simultaneously, the conservation of the environment and natural resources has become a key priority. One approach to these demands is the weight reduction of mechanical components by lightweight construction. The Transregional Collaborative Research Center (TR 10), funded by the German Research Foundation (DFG), is therefore working on the "Integration of forming, cutting and joining for the flexible production of lightweight space structures". The use of light metals, like aluminium and composite materials is a main part in the TR10 process chain. This paper deals with the challenges of welding of light weight components made out of EN AW-6060. It shows the use and potentials of two innovative joining processes, particularly suited for welding aluminium. Especially developed for the fusion welding of aluminium components, BHLW (Bifocal Hybrid Laser Beam Welding), combines a Nd:YAG and a high power diode laser. The paper will give insight into the findings of the achieved results so far and line out the further proceedings with regard to critical parameters and their effect on the overall laser welding process. For the welding of aluminium composite materials, which play a big role in the TR10 process chain, Friction Stir Welding (FSW) is evaluated. As a solid state joining process, it can be used for the welding of materials that are hardly weldable with fusion welding techniques. In this paper, results of basic experiment for the joining of reinforced aluminium and the resulting process forces are presented.
\end{abstract}

\section{Introduction}

The continuing worldwide trend towards light weight construction has led to an increasing application of light metals like aluminium. This applies not only to the use of component parts. Aluminium is also more and more utilised in light metal welded structures. Particularly in the automotive and aeronautical industry, components and welded constructions made out of aluminium and its alloys are in high demand. This development has already led to a row of innovations in joining processes trying to overcome limitations regarding the weld ability of aluminium. Yet, many of these difficulties remain still unsolved and often complicate the use of aluminium structures in industrial applications. The Transregional Collaborative Research Center (TR 10), combining the research activities of the University of Dortmund, the Universität Karlsruhe and the Technische Universität München, works on the "Integration of forming, cutting and joining for the flexible production of lightweight space frame structures". In this project, the focus of the $i w b$ lies on joining technologies for the welding of aluminium extrusion components made of EN-AW 6060 by BHLW (Bifocal Hybrid Laser Beam Welding) and FSW (Friction Stir Welding).

BHLW is investigated and developed at the $i w b$. Emphasising on investigating the inner procedures of the BHLW process and to improve the systems engineering, the first phase of the project, funded by the DFG was concluded successfully [1]. Future work packages will see to refine the welding process using novel laser sources and to integrate an online process monitoring system. 
Including a process monitoring system will allow for gaining more process knowledge and securing the weld seam quality during welding of light weight aluminium structures.

Friction Stir Welding (FSW) was developed in 1991 at The Welding Institute (TWI) in Cambridge [2] and is a solid state joining process. In this project, it is used for welding aluminium extrusion components which are reinforced by steel wires and are hardly weldable with traditional fusion welding techniques.

\section{Bifocal Hybrid Laser Beam Welding of Aluminium}

The experimental setup for the Bifocal Hybrid Laser Welding incorporates a $3 \mathrm{~kW}$ Nd:YAG laser and a $3 \mathrm{~kW}$ high power diode laser (HPDL), both integrated by one optical head and acting in the same process zone. During the first funded research period the diode laser was integrated in the optical head and the Nd:YAG laser was linked via a fibre optic cable. This resulted in a bulky optical setup with an inherent $25 \%$ loss of power from the diode laser beam by attaching it via an optical fibre cable. Transferring both lasers via fibre cable would entail that the welding process could not work because of the lack of HPDL power. The specifications of the whole welding system are defined by the lasers and the optical system. Because of the HPDL transmitted directly with a beam parameter product (BPP) of $85 \times 200 \mathrm{~mm} * \mathrm{mrad}$ a rectangular focus $(\mathrm{f}=150 \mathrm{~mm}$ ) of $0.9 \times 3.7$ $\mathrm{mm}$ can be generated. Unlike the diode laser the utilised Nd:YAG laser has a BPP of $25 \mathrm{~mm} * \mathrm{mrad}$ transformed by a focussing lens $(\mathrm{f}=150 \mathrm{~mm})$ into a circular focus with a diameter of $\mathrm{d}=0.45 \mathrm{~mm}$. By adjusting the optical system the positioning of both foci is possible and offers beneficial welding effects [3]. In Fig. 1 a measurement of their power density distribution and the relative positioning of both laser foci are displayed.

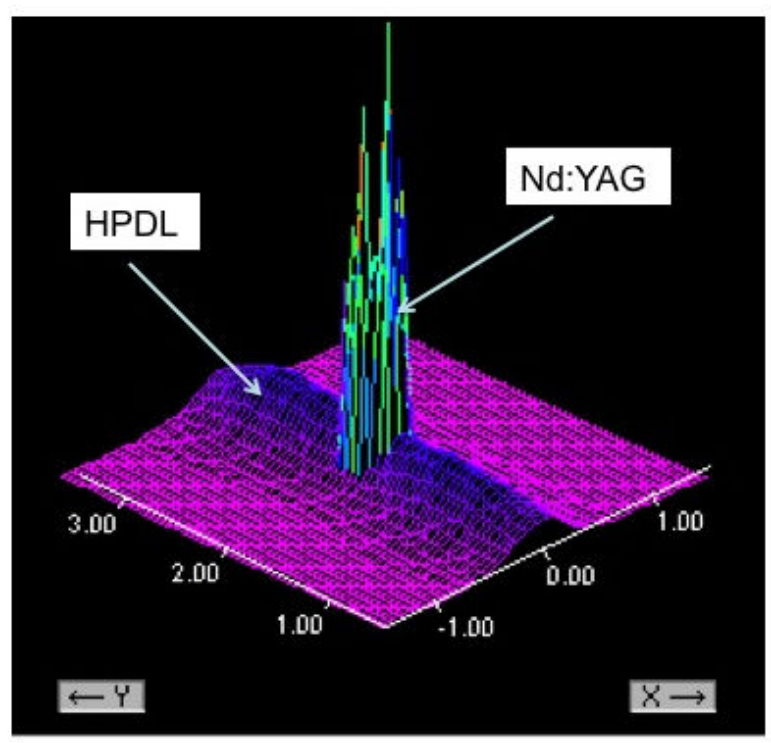

Fig. 1: The measurement of the intensity distribution of the HPDL superimposed by the $\mathrm{Nd}$ :YAG laser illustrates the relative lateral positions of the foci during BHLW

\section{Fusion Welding Characteristics of the Aluminium Alloy EN AW-6060}

The considered aluminium alloy in terms of extruded profiles of the EN AW-6060 (AlMgSi0.5) temper T66 demands the admixture of filler wire AL4046 A (SG-A1Si12) for welding to prevent hot cracks. During fusion welding some aluminium alloys tend to be susceptible to hot cracks generation [4]. Hot cracks weaken the welded joint by decreasing the tensile strength. As it could be seen in [4] the applicability of fusion welding to aluminium alloys depends a lot on the alloy's individual composition. An alloy with a concentration of $0.5 \% \mathrm{Si}$ and $0.3 \% \mathrm{Mg}$ is most uneligible 
for fusion welding [5]. Considering the composition of the used alloy EN AW-6060 the laser welding technique presented in this paper was mainly designed for laser welding of aluminium alloys tending to have hot cracks after fusion welding. Especially this certain aluminium alloy is deemed to be hardly weldable.

BHLW joins the deep penetration effect of an Nd:YAG laser with the conduction mode welding of a HPDL. The beams of the lasers are superimposed in the process zone thereby inducing several synergetic effects. By virtue of the superposition the welding process differs in energy transfer efficiency compared to the individual welding processes. However it is not yet possible to explain this synergy by consideration of data already known. Welded joints of the aluminium alloy EN AW6060 by BHLW show a significant reduction of porosity independent of the used gas in comparison to the individual Nd:YAG laser welding. Process pores emerge in aluminium because of a repeated closure of the keyhole [6]. During BHLW processing it can be assumed that the rectangular HPDL spot assists the Nd:YAG laser process. Besides the reduction of pores inside the seam, the HPDL affects the quality of the weld seam surface. The positive effects of the HPDL welding concerning surface quality of weld seams demonstrate an advantage during BHLW [3].

In the course of the first phase of TR 10 a new optical head was developed. This optical head offers a more accurate lateral and vertical positioning of the laser foci relative to each other in contrast to the optical head used during the experiments conducted in phase 1 . However, the execution of the experiments was constricted by the imprecise and limited adjustment of the foci positioning of both lasers. Consequently it is hardly possible to examine the effects of varying the relative position of the foci. An additional optical component enables the option for creating and varying the rectangular focal spot layout (Fig. 2a) of the HPDL which is essential to remove the oxide layer. In order to continue the research on the BHLW technique in terms of welding of aluminium structures the new possibilities for adjustments and more laser power will help to refine the investigations of the BHLW process. With the objective to substantiate the already existing results, experiments will be done by variation of the relative foci position of the foci in lateral and vertical direction (Fig. 2b, 2c) of two differently shaped laser spots.

The influence of focal variations should provide an indication of the interaction with geometrical, material and process parameters. Varying joint geometries, e.g. butt and lap joints, will be analysed with regard to the following seam parameters:

Joint geometry:

- welding depth

- welding width

- cross sectional area

Joint quality:

- quality of the weld seam surface

- imperfections

- disposition of the filler wire

- sensitivity to hot cracks generation 


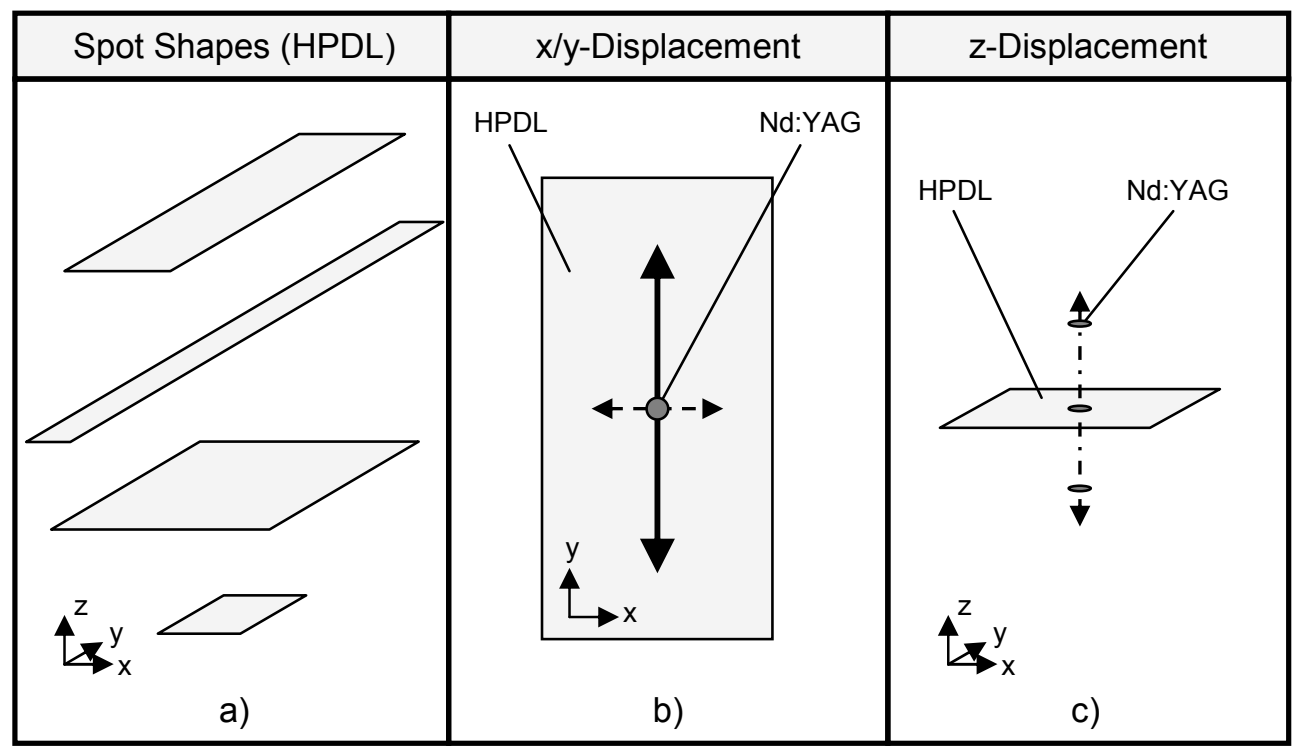

Fig. 2a, b, c: a) Various possible shapes of the HPDL focal spot. By varying the focal spot shape the welding process can be affected. b) relative displacement of HPDL and Nd:YAG focal spot in lateral direction. c) relative displacement of HPDL and Nd:YAG focal spot in vertical direction

Since welding results depend not only on parameters of adjustment, but also on the specific parameters of the laser beam, experiments will be made with two different combinations of laser sources. The combination of a $3 \mathrm{~kW} \mathrm{Nd:YAG} \mathrm{laser} \mathrm{with} \mathrm{a} 6 \mathrm{~kW}$ HPDL or an $8 \mathrm{~kW}$ fibre laser with a $6 \mathrm{~kW} \mathrm{HPDL}$ are imaginable. The deployment of the $6 \mathrm{~kW}$ HPDL will clarify the influence of the HPDL on the BHLW process. Thereby the influence on frontal oxide layer removal, magnification of the melt pool, welding depth, reduction of porosity and the homogenous disposition of filler wire can be continuously examined. Supplying two individual lasers via fibre optic cable to an enhanced optical head allows for a considerable weight reduction and reduced dimensions.
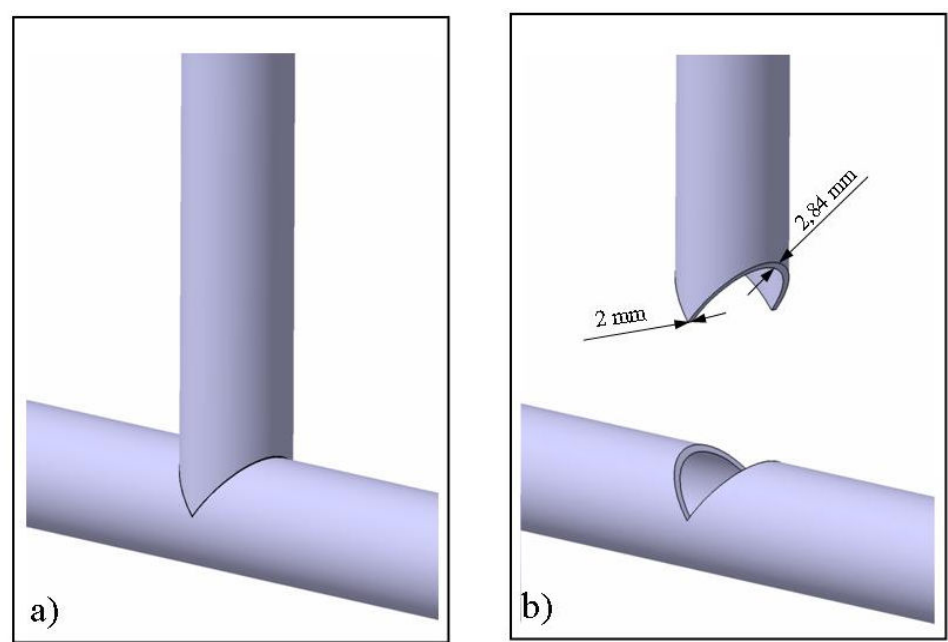

Fig. 3: T-joint of round aluminium profiles (Ø $40 \mathrm{~mm})$, a) joint geometry of the T-joint, b) modification of the thickness along the faying surfaces for welding

This step will enable an application of the BHLW to weld aluminium structures. Working with spatial structures poses the general problem of reduced accessibility in beam welding resulting in a reduced angle of incidence of the beam. Due to the substitution of the Nd:YAG laser by an $8 \mathrm{~kW}$ fibre laser investigations regarding the work piece thicknesses will be possible. This is a step towards examining the welding of structural parts. Fig. 3 shows a T-joint of round profiles with a 
diameter of $40 \mathrm{~mm}$ and faying surfaces prepared for laser welding. Alongside the cross section an increase of the welded thickness occurs.

\section{Process monitoring during BHLW}

Despite the exhibited raise in the quality of the weld seams, experiments showed that online surveillance of the process and as such assuring quality is still an issue at hand. Up to now the welding process of aluminium lacks the stability and continuity to allow for a straightforward use of online optical methods for melt pool observation and quality assurance. As the screen sequence in Fig. 4 a) demonstrates, the welding of aluminium with an Nd:YAG laser shows unstable characteristics. The images demonstrate the staggering lighting conditions during Nd:YAG laser welding. During BHLW of aluminium the lighting conditions of the welding process are in contrast quite homogeneous, as observed with a high-speed camera (Fig. 4 b)).

a) Screen sequence: Nd:YAG
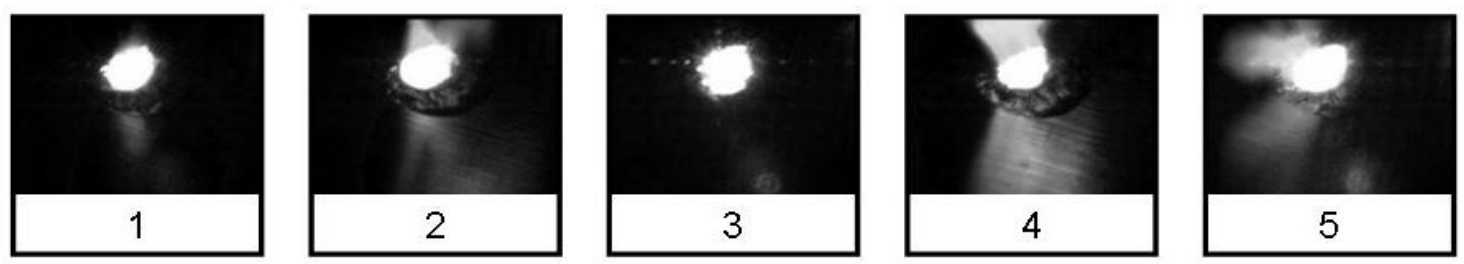

b) Screen sequence: Bifcal Hybrid Laser Welding
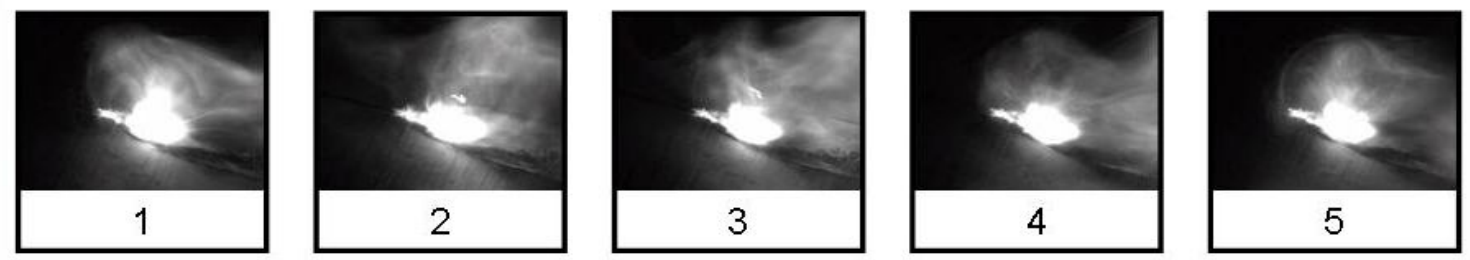

Fig. 4: Screen sequences of a high speed camera show: a) Nd:YAG welding: luminosity of the process radiation shows fluctuation b) BHLW: luminosity of the process radiation is stable

Since optical methods locate failures inside the weld seam by detecting process irregularities deviating from the process radiation during welding [7], an unstable welding process will complicate the analysis. In literature different optical methods using this principle for process monitoring can be found $[7,8,9]$. As the BHLW process shows homogeneous lighting conditions, a proper process monitoring should provide the potential to observe the process zone surface. In order to gain more information about the BHLW process, spectroscopic measurements will be done. Dimensioning for the process monitoring will be possible by analysing the spectroscopic measurements. The spectroscope measures the process radiation including the thermal radiation of the melt pool, the emissive element lines and the metal oxide molecule bands. When focussing a high power laser like an Nd:YAG laser or a fibre laser beam onto a work piece, the irradiance leads to a fast local heating and an intense evaporation of material. The evaporated material absorbs the laser radiation and generates the so called laser-induced breakdown, which means the plasma generation [10]. 
Spectroscopic measurements were done for the individual Nd:YAG welding of aluminium alloy EN AW-6060. Therefore a spectrometer sensitive for the wavelengths $380 \mathrm{~nm}$ to $880 \mathrm{~nm}$ was utilised. Fig. 5 demonstrates the experimental set-up for the spectroscopic measurements.

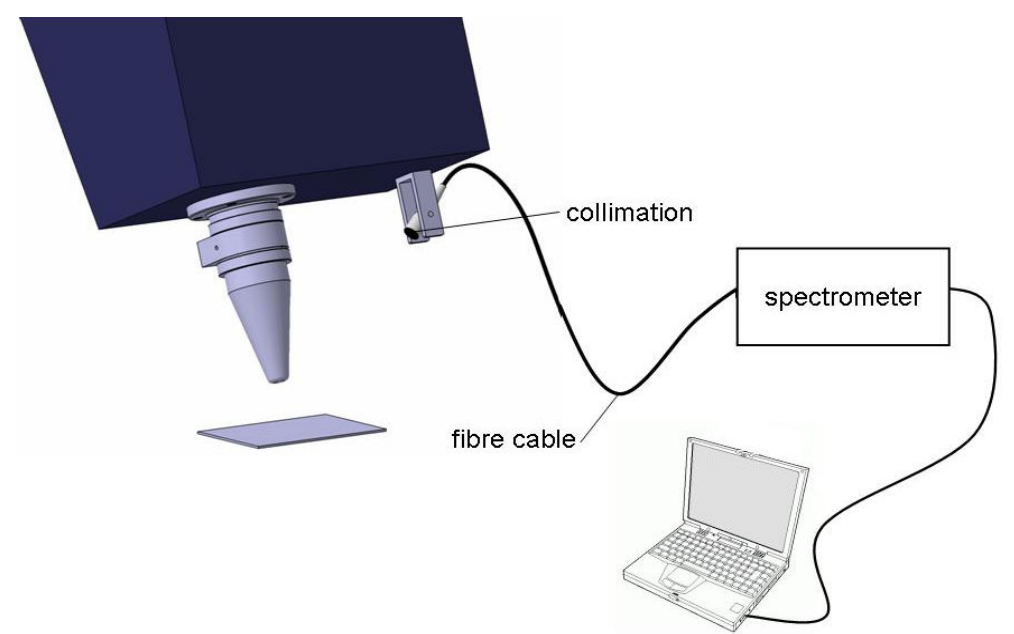

Fig. 5: Experimental set-up to measure the spectral intensity distribution during Nd:YAG welding with a spectrometer $(\lambda=380 \mathrm{~nm}-880 \mathrm{~nm})$

The collimating lens of the fibre coupled spectrometer was clamped to the bottom of the optical head and oriented towards the focal spot of the Nd:YAG laser. An additional high speed camera was implemented for documentation.

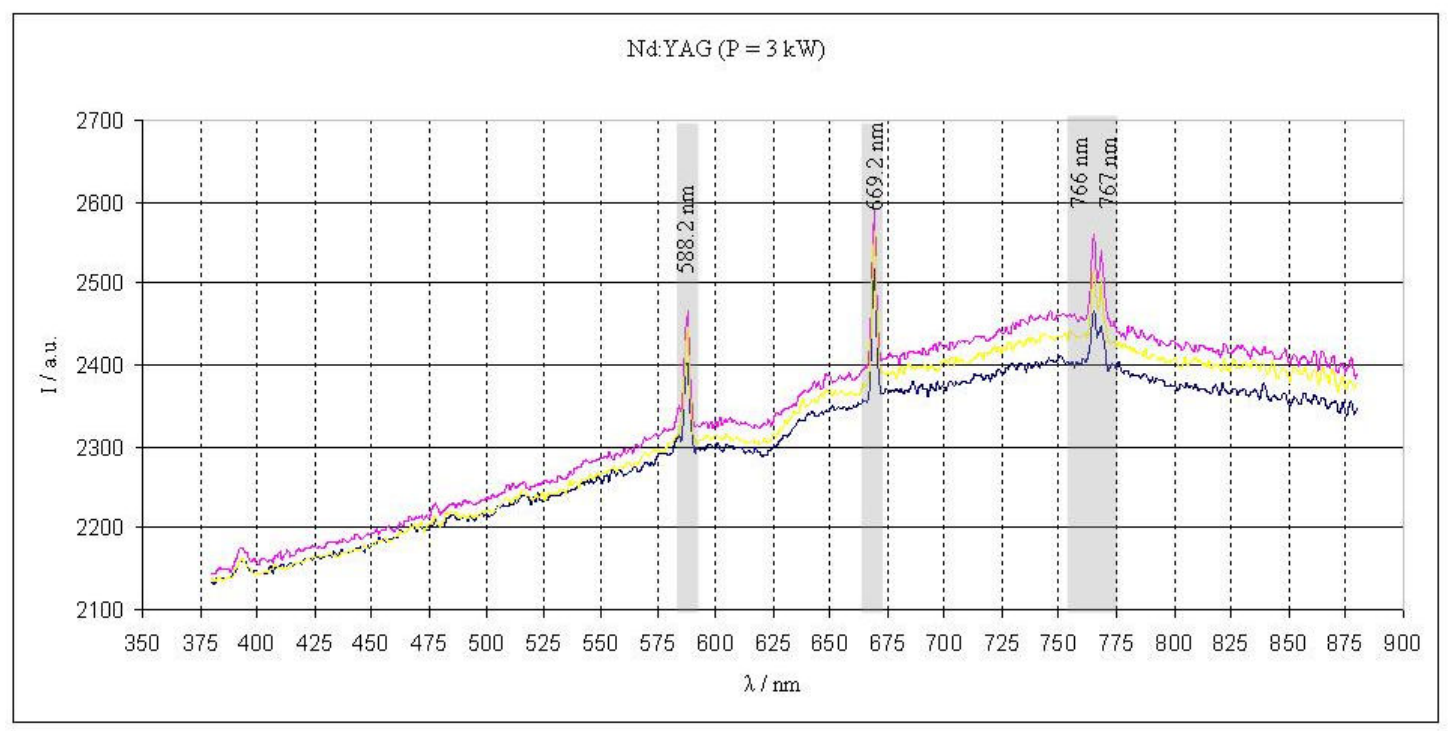

Fig. 6: Spectrum during $3 \mathrm{~kW} \mathrm{Nd:YAG} \mathrm{welding} \mathrm{of} \mathrm{EN} \mathrm{AW-6060.} \mathrm{A} \mathrm{few} \mathrm{of} \mathrm{the} \mathrm{elemental} \mathrm{lines}$ are indicated.

The result is displayed in Fig. 6 showing the spectrum of the radiation of the melt pool and plasma plume during Nd:YAG welding. For the observation of the process zone the emissive element lines and the metal oxide molecule bands will interfere, because they are caused by the transitions inside the plasma. For dimensioning the monitoring system a wavelength band area should be chosen, where no emissive element lines are, otherwise the plasma plume will be considered. To create a suitable monitoring system it is necessary to carry out spectroscopic measurements and analysis for the $6 \mathrm{~kW}$ HPDL welding as well as for the Bifocal Hybrid Laser Welding. 


\section{Friction Stir Welding of non-reinforced and reinforced aluminium alloys}

As mentioned before, BHLS is a suitable joining process for the production of high quality seams in aluminium structures. Yet, it is only applicable for the welding of homogeneous aluminium alloys. Modern materials science often develops composite materials which are supposed to be superior to their respective base materials. In the TR10, such a composite material was created. It was developed and manufactured at the Institute of Forming Technology and Lightweight Construction (IUL) of the University of Dortmund. The base material is an aluminium alloy EN AW-6060 T4 which is reinforced with six steel wires with a diameter of $1 \mathrm{~mm}$ (see Fig. 7). These wires are made out of a stainless, austenitic steel 1.4310 (X10CrNi18-8), which for example is used for pens or sheets in car production [11].

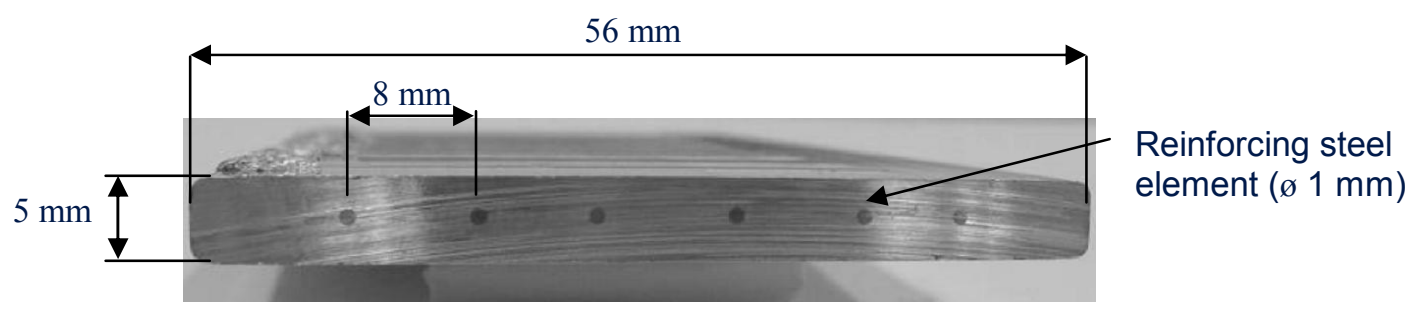

Fig. 7: Extruded EN AW-6060 T4 aluminium alloy with reinforcing elements

The nature of this composite material makes it difficult to weld with fusion welding processes like BHLW, since it would combine two materials with considerably differing properties (in terms of density, melting point, absorption coefficient etc.) in one fusion zone. Furthermore, the forming of brittle intermetallic phases is not desired. Promising results are expected to be possible with solid state joining processes which are not as susceptible to different material properties. Because of that, Friction Stir Welding (FSW) is evaluated for the joining of this composite material.

Friction Stir Welding is a solid state joining process, combining frictional and deformation heating to obtain defect free high quality joints. It is a modification of common rotary friction welding, but does not need the relative movement between the work pieces as joining is achieved by a non consumable rotating tool (see Fig. 8). This tool consists of two functional areas, the tool shoulder and the tool pin. The tool is forced into the join partners where the shoulder generates most of the frictional heat, and the welding is achieved by material transport around the tool pin. The material of the work pieces is not melted, and the temperature in the joint is kept below the liquidus line. The absence of a liquid phase during the joining process results in excellent weld quality without pores and low distortion. Drawbacks of this process are the high process forces which act upon the equipment and the joint partners.

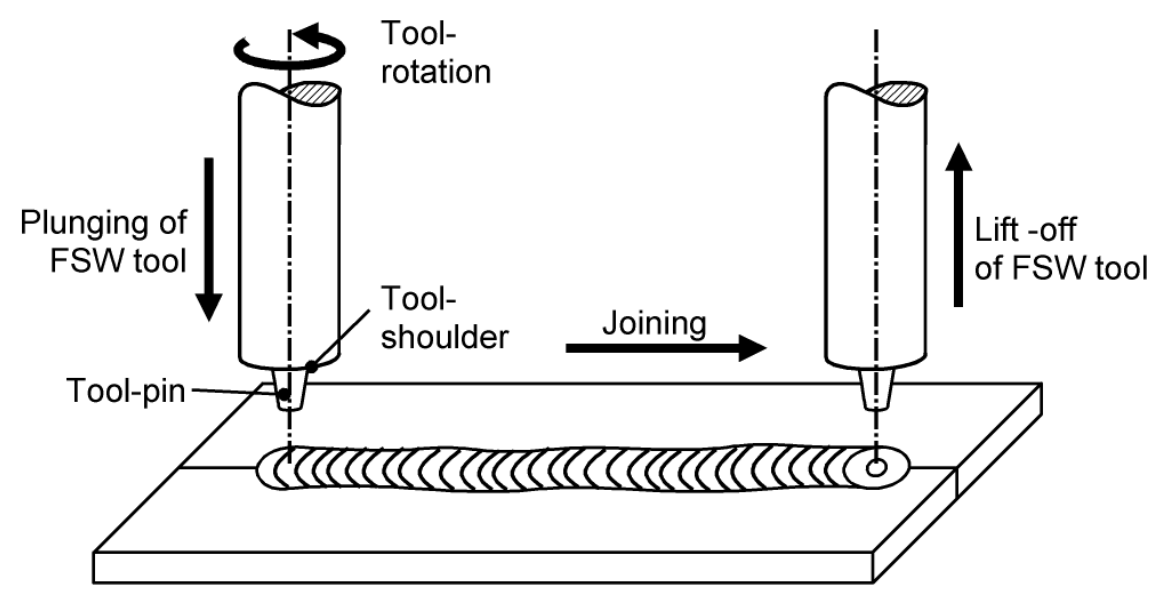

Fig. 8: Friction Stir Welding Process 
The research on FSW of reinforced aluminium extrusion alloys seeks answers to the following questions:

- How do the process forces react?

- What happens to the reinforcing elements during the welding process?

- Which consequences does this have for the strength of the joint?

All experiments were conducted on a Heller MCH 250 high performance machine tool. The used tools had a shoulder diameter of $10 \mathrm{~mm}$ with a pin diameter of 4 and $5 \mathrm{~mm}$. The length of the pin is $4.7 \mathrm{~mm}$. All welds are done with a tilt angle of the tool of $2^{\circ}$ and a programmed plunge depth of the tool shoulder of $0.2 \mathrm{~mm}$.

\section{Friction Stir Welding of non-reinforced Aluminium}

As mentioned before, the focus of this study is to weld extruded aluminium profiles, reinforced with steel wires. In order to successfully join this composite material it is necessary to know how the base material reacts during friction stir welding. Therefore the weld properties of the base material are explored beforehand. The base material is an aluminium extrusion alloy, EN AW-6060 (AlMgSi0.5) tempered T4, with dimensions $56 \mathrm{~mm}$ x $5 \mathrm{~mm}$. There are two reasons for preliminary weld experiments with the base material:

- Finding a parameter window for the non-reinforced aluminium as a basis for weld experiments for the reinforced alloy

- Documenting the process forces during welding in order to compare the forces with these occurring during welding of the composite material

The varied parameters for these tests were the rotation speed of the tool and the welding speed. They were changed from $500 \mathrm{rpm}$ to $1500 \mathrm{rpm}$ and $100 \mathrm{~mm} / \mathrm{min}$ to $300 \mathrm{~mm} / \mathrm{min}$ respectively.

To evaluate the process parameters, metallographic analysis was conducted for each weld. A cross section of a defect free and a flawed joint are shown in Fig. 9a and accordingly 9b. The weld joint in Fig. 9a was manufactured with a welding speed of $200 \mathrm{~mm} / \mathrm{min}$ and a rotation speed of $1250 \mathrm{rpm}$. The other cross section in Fig. 9b shows a joint welded with a rotation speed of $1500 \mathrm{rpm}$ and a welding speed of $400 \mathrm{~mm} / \mathrm{min}$. These parameters led to a flawed joint very likely caused by too little heat input [12] resulting from the high welding speed. Cavities in the lower area oft the FSW-nugget occur in all welds with too little heat input. According to these results, the process window for further tests with reinforced aluminium components was set to a range of $750 \mathrm{rpm}$ to $1500 \mathrm{rpm}$ and $100 \mathrm{~mm} / \mathrm{min}$ to $200 \mathrm{~mm} / \mathrm{min}$.

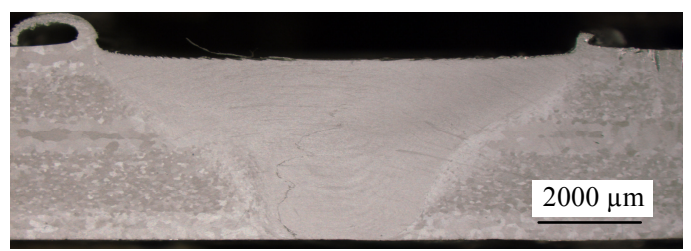

a)

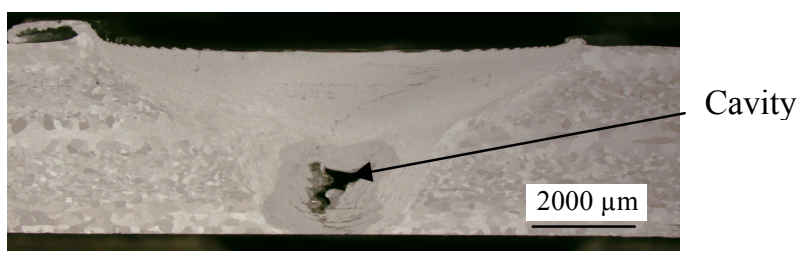

b)

Fig. 9: Metallographic cross section of friction stir welded aluminium without reinforcing elements a) without cavity b) with cavity

During these preliminary tests, the downward force and the force in weld direction were recorded by the control system of the machine tool. Generally, forces tend to rise with colder welds. In the chosen parameter window, downward forces range from $2 \mathrm{kN}$ to $5 \mathrm{kN}$, forces in weld direction lie between $0.3 \mathrm{kN}$ to $1 \mathrm{kN}$. 


\section{Friction Stir Welding of reinforced Aluminium}

With the specified process window, butt joints of reinforced aluminium sheets were welded. The orientation of the steel wires in the aluminium sheets is illustrated in Fig. 10. It also shows how the reinforcing elements are deformed during welding. Regarding the surface of the welded parts, the reinforcing elements in profile 1 seem to be bent upwards and downwards in profile 2 . This fact is supposed to be caused by the thread of the FSW-pin which creates a vortex of plasticized material in the weld zone.

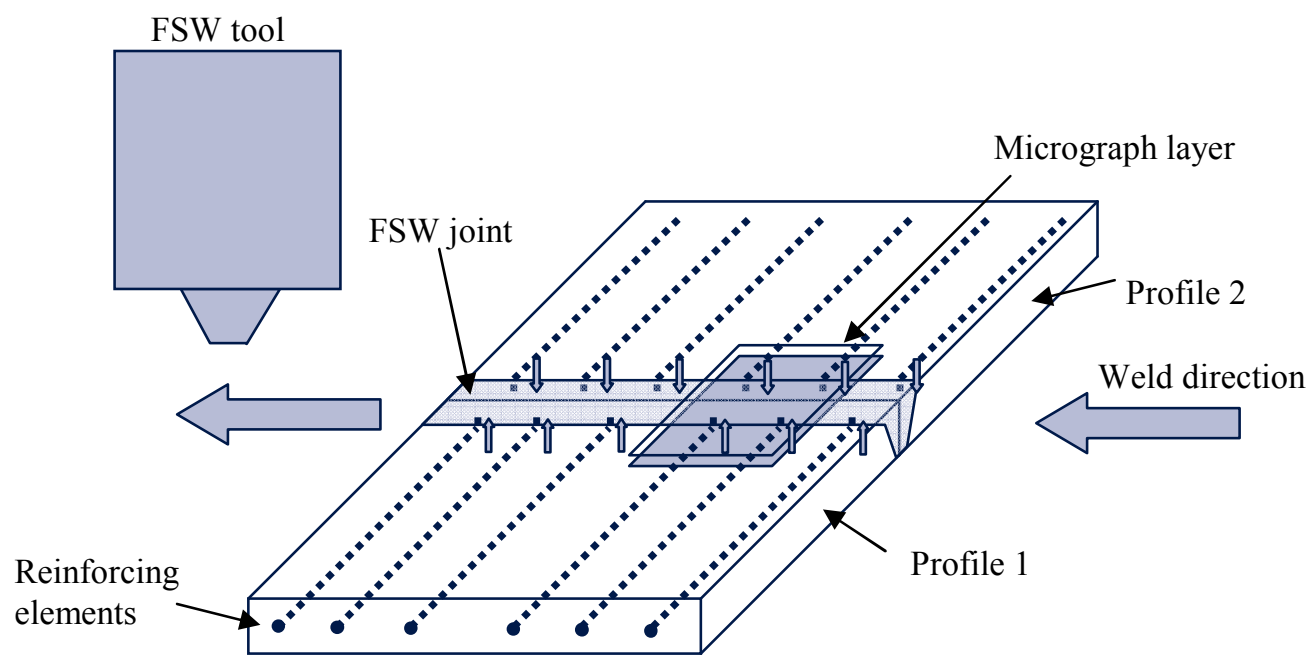

Fig. 10: Deformation of reinforcing elements during the welding process

This is also observable in the top view of an FSW weld seam. While welding through the location of the steel wires, aluminium is pushed upwards and creates clearly recognizable bumps the surface (see Fig.11).

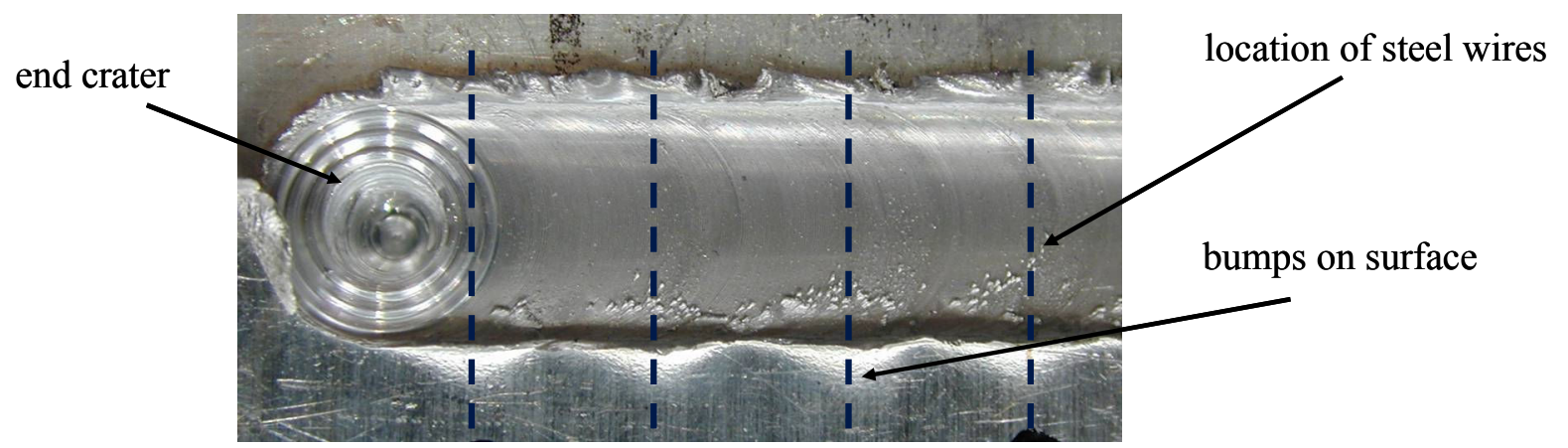

Fig. 11: Top view on FSW weld seam of reinforced aluminium alloy

Fig. 10 also shows the layer of the micrographs, displayed in Fig 12. They were made by the Institute of Material Science and Engineering 1 at the Universität Karlsruhe as a part of the TR10. Both micrographs were taken in a depth of about two millimetres from the surface and include two wires. Because of the deformation mentioned before, only one half of the wires can be seen. The micrographs hold further information on what happens to the steel wires during the welding process. Fig. 12a and Fig. 12b exemplarily show two welds with different process parameters. The joints were welded with a welding speed of $150 \mathrm{~mm} / \mathrm{min}$ and a rotation speed of $750 \mathrm{rpm}$ and $1250 \mathrm{rpm}$. The welding direction and rotation of the tool are indicated with arrows. The influence of the rotation speed on the reinforcing elements can clearly be seen in these micrographs. At lower rotation speeds, the steel wires are deformed towards the weld direction which leads to cavities in the direct vicinity of the steel wires. At higher rotation speed, the tips of the wires are smashed into 
little fragments which are distributed over the weld zone in the wake of the tool. This directly influences the mechanical properties of the joints. Further studies on these effects, including the determination of the tensile strength at different welding parameters, were done by the Institute of Material Science and Engineering 1 and are presented in [13].

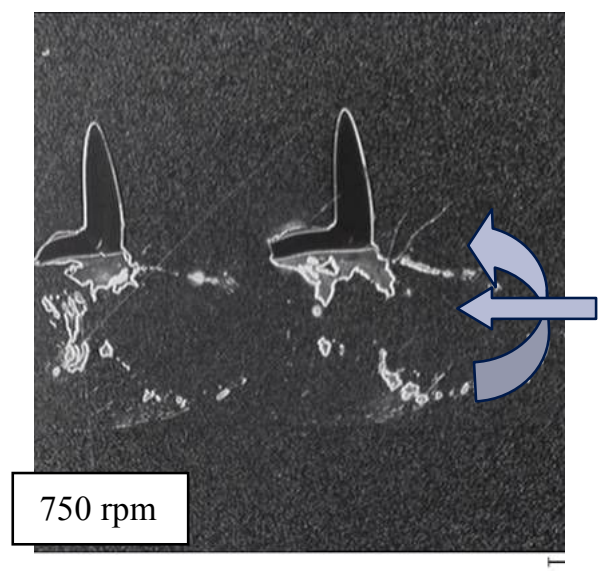

a)

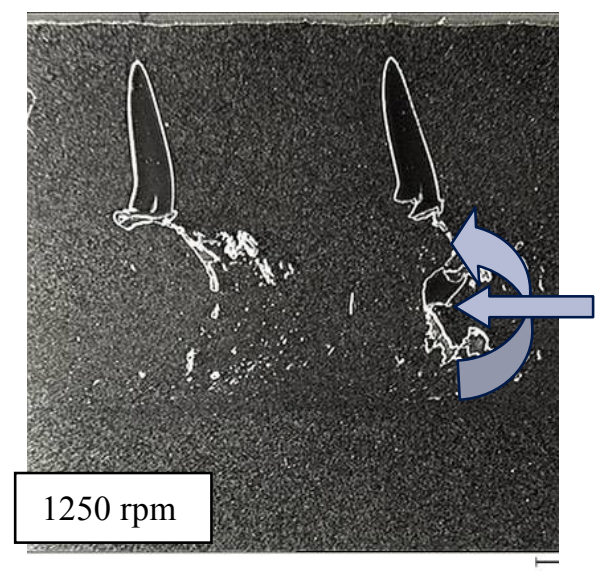

b)

Fig. 12: Micrographs of friction stir welded reinforced extruded aluminium, a) rotation speed $750 \mathrm{rpm}$, welding speed $150 \mathrm{~mm} / \mathrm{min}$, b) rotation speed $1250 \mathrm{rpm}$, welding speed $150 \mathrm{~mm} / \mathrm{min}$

As mentioned before, next to the mechanical properties, the effect of the steel wires on the process forces was investigated. These forces act upon the FSW machine and on the joint partners. For aluminium parts with sufficient backing, process forces can often be neglected. For more complex aluminium structures, which are considered in the TR10, process forces are of fundamental importance. Generally, downward forces during FSW are considerably higher than forces along the joint line $[14,15]$. Fig. 13 shows representative downward forces and forces in welding direction during the welding of non-reinforced and reinforced aluminium sheets. The overall magnitude of the forces during welding is the same for both types of material. Yet, there is a big discrepancy in the curve progressions between plain aluminium and the composite material. The downward force reacts abruptly at the location of the steel wires, whereas the force along the joint line increases and decreases more gradually. The value of the force along the joint line during welding of composite material is always higher than for plain aluminium, whereas the downward force oscillates around the value during welding of the base material.

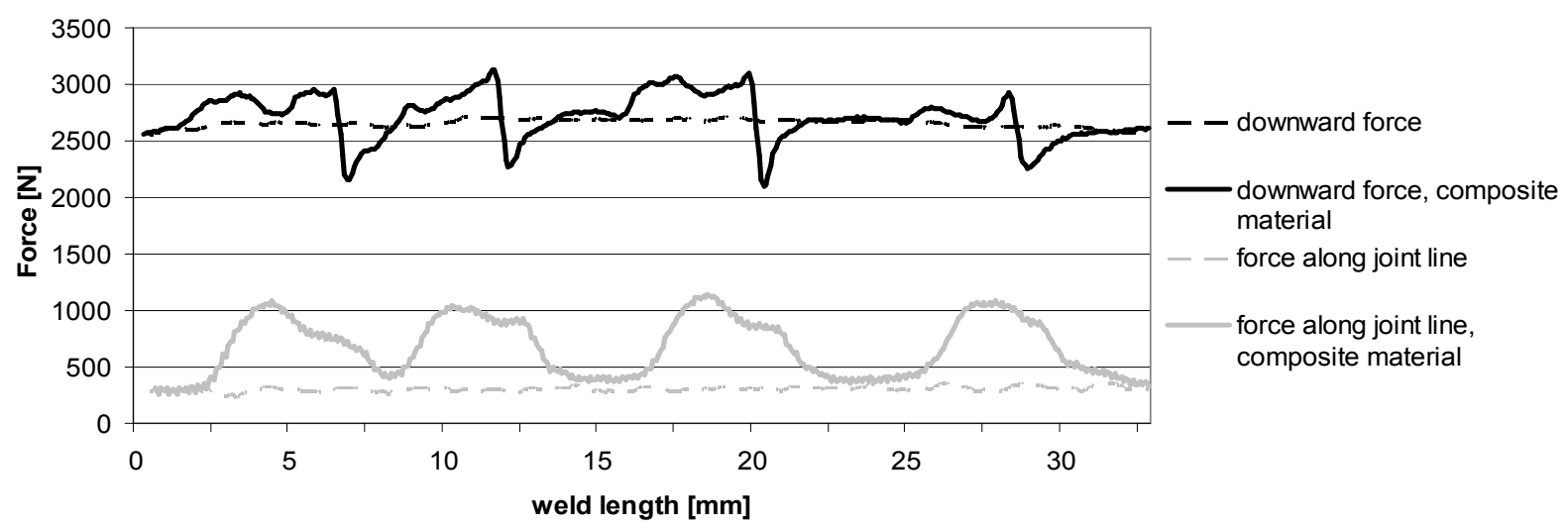

Fig. 13: Process forces during welding (rotation speed $1250 \mathrm{rpm}$, welding speed $200 \mathrm{~mm} / \mathrm{min}$ )

The weld experiments show that there is a relationship between weld parameters and process forces. As mentioned before, both forces tend to rise with colder welds. For the forces in the direction of 
the joint line, it can be noticed, that force peaks rise for colder welds, whereas such a correlation can not be recognized for the downward forces.

\section{Conclusion}

The research work up to now demonstrated the feasibility of Bifocal Hybrid Laser Welding of aluminium alloys. It was shown that certain requirements of industrial manufacturing, e.g. a reproducible and stable process, are met by this technique. This paper aimed at presenting current and future work, concentrating on its further proceedings. The prototypical optical head will be substituted by a more compact design allowing new fields of application together with the integration of new laser technologies. The implementation of a method for process monitoring will underpin the already existing advantages of BHLW of aluminium alloys.

For components that can not be joined with BHLW, like composite materials, Friction Stir Welding was presented to be a suitable alternative. The principle weldability of aluminium sheets, reinforced with steel wires could be shown. Furthermore, the relationship between process parameters and the process forces during FSW of reinforced aluminium was presented, which is a basis for adapting the process to join more complex aluminium structures. Future work will concentrate on extending the flexibility of the process, regarding the geometry of parts that are to be welded. Additionally, further experiments concerning weld quality and the resulting mechanical properties are planned. As a final step, these results will be used as a basis for experiments on the welding of aluminium with non-metallic reinforcing elements.

\section{Acknowledgements}

This paper is based on investigations of the Transregional Collaborative Research Centre SFB/TR10, which is kindly supported by the German Research Foundation (DFG).

\section{References}

[1] A. Trautmann and M. F. Zaeh: Prozesssicheres Fügen von Aluminium-Tragwerksstrukturen mit einem hybriden, bifokalen Lasersystem. In: M. Kleiner, H. Baier, J. Fleischer, D. Löhe , K. Weinert, M. F. Zaeh, and M. Schikorra (Eds.): Integration von Umformen, Trennen und Fügen für die flexible Fertigung von leichten Tragwerkstrukturen, Fortschritt-Berichte VDI: Ergebnisbericht der Phase 1, Jan. 2003 Dez. 2006, Duesseldorf, Germany, Reihe 2, pp. 153 - 181

[2] W. M. Thomas, International Patent 9,310,935. (1993)

[3] A. Trautmann and M. F. Zaeh: Laser Bifocal Hybrid Welding of Aluminium. In: M. Kleiner, J. Fleischer, M. F. Zaeh and M. Schikorra (Eds.): Advanced Materials Research: Flexible Manufacture of Lightweight Frame Structures, 2006, Germany, Vol. 10, pp. $65-77$

[4] S. Huber, A. Trautmann and M. F. Zaeh: Bifocal Hybrid Laser Welding of Aluminium. In: A. Geiger, A. Otto and M. Schmidt (Eds.): Proceedings of Laser Assisted Netshape Engineering, 2007, Erlangen, Germany, Volume 2

[5] M. Beckert and H. Herold: Kompendium der Schweißtechnik - Band 3: Eignung metallischer Werkstoffe zum Schweißen (DVS Verlag, Germany 2002). 
[6] A. Trautmann, S. Roeren and M. F. Zaeh: Welding of Extruded Aluminium Profiles by a Hybrid Bifocal Laser System. In: A. Geiger and A. Otto: Proceedings of Laser Assisted Netshape Engineering, 2005, Erlangen, Germany, Volume 1

[7] B. Denkena; R. Kling, U. Stute, A. Moalem and T. Hesse: Quality control in laser welding with fast inline spectral analysis of the process radiation. In: F. Vollersten, C. Emmelmann, M Schmidt and A. Otto: Lasers in Manufacturing 2007, June 18.-22., 2007, Munich, Germany, pp. 477 - 481

[8] M. Dahmen, W. Fiedler, B. Regaard and S. Kaierle: Continuous process control during laser beam welding of small section Aluminium sheet. In: F. Vollersten, C. Emmelmann, M. Schmidt and A. Otto: Lasers in Manufacturing 2007, June 18.-22., 2007, Munich, Germany, pp. 471 - 475

[9] J. Müller-Borhanian, C. Deininger, F. H. Dausinger and H. Hügel: Spatially resolved Online Monitoring during Laser Beam Welding of Steel and Aluminium. In: International Congress on Applications of Lasers \& Electro-Optics, October 4.-7., 2004, San Francisco, USA

[10] I. Radivojevic: Spectrochemical Analysis of Solid Samples by Laser-induced Plasma Spectroscopy. (Dissertation Technische Universität München, 2004, Munich, Germany)

[11] EN 10088-1: Stainless steels - Part 1: List of stainless steels. Beuth, 2005, Berlin, Germany

[12] Y. G. Kim, H. Fujii, T. Tsumura, T. Komazaki and K. Nakata: Three defect types in friction stir welding of aluminium die casting alloy. In: Materials Science and Engineering, Part A, 2006, Volume 415, pp.250-254

[13] P. Barreiro, V. Schulze and D. Löhe: Influence of Process Parameters on Structure and Mechanical Properties of Joints produced by Electromagnetic Forming and Friction Stir Welding. In Advanced Materials Research: Flexible Manufacture of Lightweight Frame Structures, 2008, Germany

[14] D. Eireiner: Prozessmodelle zur statischen Auslegung von Anlagen für das Friction Stir Welding. (iwb Forschungsberichte, 2006, Munich, Germany)

[15] R. Johnson.: Forces in Friction Stir Welding of Aluminium Alloys. In: TWI Ltd. (Ed.): Proceedings of $3^{\text {rd }}$ International Friction Stir Welding Symposium, September 27.-28., 2001, Kobe, Japan 